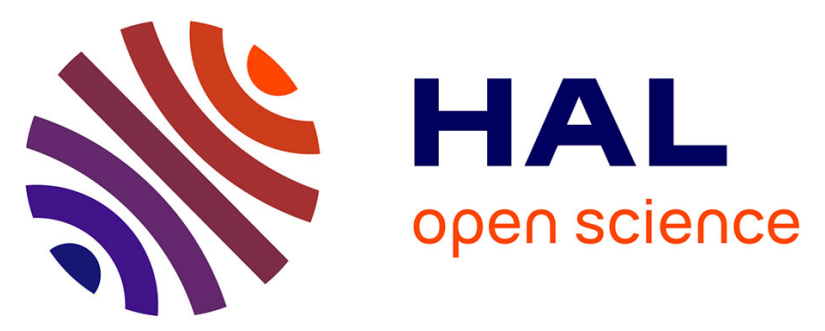

\title{
Disturbance of Metabotropic Glutamate Receptor-Mediated Long-Term Depression (mGlu-LTD) of Excitatory Synaptic Transmission in the Rat Hippocampus After Prenatal Immune Challenge
}

Mélanie Cavalier, Azza Ben Sedrine, Lea Thevenet, Nadine Crouzin, Janique Guiramand, Marie-Céleste de Jesus Ferreira, Catherine Cohen-Solal, Gérard Barbanel, Michel Vignes

\section{- To cite this version:}

Mélanie Cavalier, Azza Ben Sedrine, Lea Thevenet, Nadine Crouzin, Janique Guiramand, et al.. Disturbance of Metabotropic Glutamate Receptor-Mediated Long-Term Depression (mGlu-LTD) of Excitatory Synaptic Transmission in the Rat Hippocampus After Prenatal Immune Challenge. Neurochemical Research, 2019, 44 (3), pp.609-616. 10.1007/s11064-018-2476-0 . hal-01829099

\section{HAL Id: hal-01829099 https://hal.science/hal-01829099}

Submitted on 28 Jan 2020

HAL is a multi-disciplinary open access archive for the deposit and dissemination of scientific research documents, whether they are published or not. The documents may come from teaching and research institutions in France or abroad, or from public or private research centers.
L'archive ouverte pluridisciplinaire $\mathbf{H A L}$, est destinée au dépôt et à la diffusion de documents scientifiques de niveau recherche, publiés ou non, émanant des établissements d'enseignement et de recherche français ou étrangers, des laboratoires publics ou privés. 
Disturbance of metabotropic glutamate receptor-mediated long-term depression (mGluLTD) of excitatory synaptic transmission in the rat hippocampus after prenatal immune challenge.

Mélanie Cavalier, Azza Ben Sedrine, Lea Thevenet, Nadine Crouzin, Janique Guiramand, Marie-Céleste de Jésus Ferreira, Catherine Cohen-Solal, Gérard Barbanel, Michel Vignes

UMR5247 Institut des Biomolécules Max Mousseron - University of Montpellier-CNRS-ENSCM, Team 'Pharmacochemistry of Synaptic transmission and Neuroprotection'

University of Montpellier- Sciences Faculty

Place E Bataillon, 34095 Montpellier cedex 05, France

Corresponding author:

Michel Vignes

michel.vignes@umontpellier.fr 


\begin{abstract}
Maternal immune challenge has proved to induce moderate to severe behavioral disabilities in the offspring. Cognitive/behavioral deficits are supported by changes in synaptic plasticity in different brain areas. We have reported previously that prenatal exposure to bacterial LPS could induce inhibition of hippocampal long-term potentiation (LTP) in the CA1 area of the juvenile/adult male offspring associated with spatial learning inabilities. Nevertheless, deficits in plasticity could be observed at earlier stages as shown by the early loss of long-term depression (LTD) in immature animals. Moreover, aberrant forms of plasticity were also evidenced such as the transient occurrence of LTP instead of LTD in 15-25 day-old animals. This switch from LTD to LTP seemed to involve the activation of metabotropic glutamate receptor subtype 1 and 5 (mGlu1/5). We have thus investigated here whether the long-term depression elicited by the direct activation of these receptors (mGlu-LTD) with a selective agonist was also disturbed after prenatal stress. We find that in prenatally stressed rats, mGlu1/5 stimulation elicits long-term potentiation (mGlu-LTP) independently of $\mathrm{N}$-methyl-D-aspartate receptors. Both mGlu5 and mGlu1 receptors are involved in this switch of plasticity. Moreover, this mGlu-LTP is still observed at later developmental stages than previously reported, i.e. after 25 day-old. In addition, increasing synaptic GABA with tiagabine tends to inhibit mGlu-LTP occurrence. By contrast, long-term depression induced with the activation of CB1 cannabinoid receptor is unaffected by prenatal stress. Therefore, prenatal stress drastically alters mGlu1/5-associated plasticity throughout development. MGlu-mediated plasticity is an interesting parameter to probe the long-lasting deficits reported in this model.
\end{abstract}




\section{Introduction}

Uncontrolled infection during pregnancy can increase the risk for the occurrence of neurodevelopmental disease in children, including autism or attention deficit hyperactivity disorder [1-3]. To some extent, rodent models of prenatal immune challenge recapitulate the behavioral deficits observed in the course of these diseases. Exposing dams to bacterial LPS results in the occurrence of cognitive, social, and behavioral deficits in the offspring [4]. Such deficits are reminiscent of 'psychotic-like' conditions in humans. For instance, probing prepulse inhibition reflex, a hallmark of 'psychotic-like' estate, demonstrated that prenatal LPS could reduce the effectiveness of this reflex [4]. These cognitive/behavioral deficits are underlined by severe impairments, even loss, of synaptic plasticity as evidenced by the inability to trigger long-term potentiation (LTP) or long-term depression (LTD) of excitatory synaptic transmission in the hippocampi from these animals [5-7]. As we reported previously, these changes may originate from various molecular/cellular mechanisms including a disruption of the excitatory/inhibitory balance. Firstly, we have evidenced a reduction in GABAergic synaptic transmission. Interestingly, reinstating GABA with type 1 GABA transporter (GAT1) blocker, i.e. tiagabine, restored LTD [8]. Functional deficits of inhibitory transmission are matched with reduced GABAergic interneuron occurrence in CA3 hippocampal area [8]. Secondly, synaptic NMDA receptor function is decreased after prenatal LPS challenge [7]. In the hippocampus, LTP and LTD are largely dependent on the activation of postsynaptic NMDA receptors [9]. The loss of these phenomena observed in LPS animals is time matched with the decrease of NMDA receptor expression in hippocampal neurons [7]. Nevertheless, the activity of other glutamate receptors may also be disturbed after prenatal stress leading to the occurrence of aberrant forms of synaptic plasticity. This seems to be the case of phospholipase C-coupled metabotropic glutamate receptors (mGlu1/5). Indeed, we observed that a form of LTD induced by paired-pulse afferent stimulation, which involves mGlu1/5 activation [10], was transiently converted into an LTP after prenatal stress. The pharmacological blockade of mGlu1 or mGlu5 receptors leads to the inhibition of this 'aberrant' LTP. By contrast, this 'aberrant' LTP was completely independent of NMDA receptor activation [7].

The direct activation of mGlu1/5 with selective agonist as dihydroxyphenylglycine (DHPG) leads to LTD (mGlu-LTD) in the rodent hippocampus [10-13]. This form of plasticity has received much attention as it is very sensitive to the occurrence of pathological states [13]. Indeed, animal models of multiple brain pathologies, including FMRX-linked mental retardation [14], drug addiction [15-16], autism [17] are displaying alterations of this form of plasticity. We have thus decided to test whether the mGlu-LTD in the CA1 area of the hippocampus was altered after immune prenatal stress and whether these putative alterations shared similarities with those unveiled for electrically-induced LTD. 


\section{Materials and methods}

Drugs

$(R S)$-3,5-Dihydroxyphenylglycine (DHPG), D-2-amino-5-phosphonovalerate (D-AP5), 2-Methyl-6(phenylethynyl)pyridine hydrochloride (MPEP), dizolcipine (MK-801), (S)-(+)- $\alpha$-Amino-4-carboxy-2methylbenzeneacetic acid (LY 367385) and tiagabine hydrochloride were from Tocris (BioTechne). All other drugs were from Sigma-Aldrich (Merck).

\section{Animal groups}

All experiments were carried out in accordance with the European Community Council Directive of November 24, 1986 (86/609/ECC). This study was approved by the local branch of the 'Comit National de Reflexion Ethique sur l'Experimentation Animale' (CNREEA nu 36) under the reference CEEA-LR-12099. All efforts were made to minimize animal suffering and to reduce the number of rats used.

Pregnant Sprague-Dawley rats (Centre d'Elevage Depré, St Doulchard, France) were used throughout this study. Animals were housed individually and randomly assigned to either of these experimental groups: (i) a group of control animals born to saline-injected dams $\left(2 \mathrm{ml}^{-\mathrm{kg}^{-1}}\right.$ ip at the $19^{\text {th }}$ day of gestation GD19) (SAL rats) or (ii) a group of animals born to LPS-treated dams (500 mg.kg ${ }^{-1}$ ip at GD19) (LPS rats). LPS (from Escherichia coli, serotype 055:B5) was obtained from Sigma-Aldrich (Saint-Quentin Fallavier, France). After birth, the size of the litters was limited to ten pups. All animals were maintained on a 12-hr light/dark cycle with food and water ad libitum.

\section{Electrophysiological recordings with micro-electrode array}

Experiments were carried out on hippocampal slices (300 $\mu \mathrm{m}$ thickness) obtained from 11 to 180 day-old male offspring. After decapitation, brains were quickly dissected and placed in ice-cold buffer comprising $124 \mathrm{mM} \mathrm{NaCl}, 3.5 \mathrm{mM} \mathrm{KCl}, 25 \mathrm{mM} \mathrm{NaHCO}_{3}, 1.25 \mathrm{mM} \mathrm{NaH}_{2} \mathrm{PO}_{4}, 1 \mathrm{mM} \mathrm{CaCl}, 2 \mathrm{mM}$ $\mathrm{MgSO}_{4}, 10 \mathrm{mM}$ D-glucose, and $10 \mathrm{mM}$ HEPES (bubbled with $\mathrm{O}_{2} / \mathrm{CO}_{2}, 95 / 5$ ). Slices were then cut with a Vibratome (VT1000S; Leica, France) and maintained at RT for at least $1 \mathrm{~h}$ in the same buffer supplemented with $1 \mathrm{mM} \mathrm{CaCl}$. This supplemented buffer - also named extracellular medium - was used for further recordings.

For electrophysiological recordings, slices were transferred to a MEA (MEA60; Multi Channel Systems, Reutlingen, Germany) continually superfused with the above described extracellular medium (flow rate $2 \mathrm{ml} . \mathrm{min}^{-1}$ ) and kept at $32^{\circ} \mathrm{C}$. Unless otherwise stated, this medium included AP5 $(50 \mu \mathrm{M})$ a NMDA receptors selective antagonist. Drugs were directly applied in this superfusion. MEA was positioned on the platform of an inverted microscope (DMLFS, Leica). MEAs comprised 60 extracellular electrodes [6]. The inter-electrode distance was $200 \mu \mathrm{m}$. Each individual electrode from the array could be used either as a recording or as a stimulatory electrode. A nylon mesh was positioned above the slice to obtain a satisfactory electrical contact between the surface of the slice and the electrode array. Stimulation was achieved with an external stimulator (STG-1004; Multi Channel Systems) by applying biphasic current pulses to one electrode of the array located in the Schaffer Collateral pathway of the hippocampus. Stimulation intensity (60 to $300 \mu \mathrm{A})$ and duration (70 to $200 \mu \mathrm{s}$ ) were adapted to avoid multiphasic responses due to an excessive stimulation [18]. Field excitatory postsynaptic potentials (fEPSPs) could then be recorded in the stratum radiatum of the CA1 subfield by all the remaining electrodes of the array at the same time. The fEPSP recorded by 
the electrodes adjacent to the stimulating one were used for further analysis (see [19]). Signals were recorded and analyzed (MC Rack; Multi Channel Systems). Baseline synaptic signals were evoked using a $0.066 \mathrm{~Hz}$ frequency. Slices displaying epileptic-like activity were discarded. The magnitude of the effects on synaptic transmission was determined by measuring slopes of fEPSPs, which were modified in a similar way to fEPSP amplitudes, as reported by others also using MEA recordings [20]. Data are presented as means \pm SEM on graphs plotting pooled data. Each individual (' $n$ ') corresponds to an experiment performed on a slice from an individual animal. Pooled data were obtained from animals originating from at least three independent litters in order to avoid possible litter-specific effects.

\section{Statistical analyses}

Statistical analyses were performed using Sigma Stat software. Single curves were analyzed using ANOVA on repeated measures, followed by Holm-Sidak method for multiple comparisons. Curve comparisons were performed using two-way ANOVA, followed by Holm-Sidak method for multiple comparisons. Means of plateau fEPSP amplitudes were compared using ANOVA followed by Fisher LSD method, or t-test when comparing two groups. 


\section{Results}

In a first set of experiments (Figure 1), hippocampal slices from rats subjected to prenatal exposure either to saline (SAL-rats) or to LPS (LPS-rats) were treated with DHPG $(100 \mu \mathrm{M})$. In the age range tested, i.e. 16- to 180-day-old rats, mGlu-LTD (LTD amplitude of $14 \pm 6 \%$ of basal) was triggered by DHPG in SAL rats $(n=17)$. By contrast, an enduring potentiation of excitatory transmission (LTP amplitude of $52 \pm 15 \%$ of basal) was observed consistently in LPS rats after DHPG application $(n=19)$. Therefore, it appears that mGlu-LTD is converted in an 'mGlu-LTP' after prenatal exposure to LPS.

All further experiments were carried out in the presence of AP5 $(50 \mu \mathrm{M})$, a NMDA receptor antagonist, in order to eliminate NMDA receptor contribution to DHPG-induced actions and thus to evaluate mGlu1/5 receptor-mediated effects more specifically on synaptic transmission. In control animals (SAL, $n=20$ ), mGlu-LTD was substantially lost under NMDA receptor blockade (Figure 2). In fact when comparing the whole curves obtained either in the presence or the absence of AP5 using two-way ANOVA, we found that a statistical significance could be observed 30 min post DHPG $(p=0.05)$ which became stronger $40 \mathrm{~min}$ after DHPG $(p=0.03)$. This could be attributable to an increasing recruitment with time of NMDA receptors for the expression of mGlu-LTD.

By contrast, mGlu-LTP in LPS animals $(n=29)$ was completely insensitive to such application of AP5 (Figure 2A and $\mathrm{B}$ ). When separating data obtained in rats the age range 11- to 25-day-old from those obtained rats older than 25-day-old (up to 180-day-old), it appears that this DHPG-induced LTP was consistently observed throughout development (Figure 3).

The dependence of mGlu-LTD on mGlu1 or mGlu5 activation was further studied in 11-25 day-old SAL rats with selective antagonists of these receptors i.e. LY367385 $(100 \mu \mathrm{M}, \mathrm{n}=7)$ [21] and MPEP $(10 \mu \mathrm{M}$, $n=5$ ) [22], respectively. Both antagonists could block efficiently and individually the induction of mGlu-LTD (Figure 4A and B). We have next examined whether mGlu1 or mGlu5 receptor blockade could also prevent mGlu-LTP occurrence in LPS rats. LY367385 $(100 \mu \mathrm{M}, \mathrm{n}=9)$ and MPEP $(10 \mu \mathrm{M}, \mathrm{n}=$ 6) were both able to inhibit mGlu-LTP occurrence (Figure 5A). The GAT-1 blocker tiagabine $(20 \mu \mathrm{M}, \mathrm{n}$ = 5) was further tested on the DHPG-induced synaptic plasticity in LPS animals. Indeed, we have previously demonstrated that prenatal LPS challenge induced a deficit in the inhibitory GABAmediated synaptic transmission [8]. The application of tiagabine led to the inhibition of mGlu-LTP occurrence in rats subjected to prenatal stress (Figure 5B).

Finally, we have examined whether the type one cannabinoid receptor (CB1R)-associated LTD was also disrupted after prenatal stress. Indeed, CB1R and mGlu1/5 receptor activations are often associated in the regulation of synaptic plasticity, especially LTD in the hippocampus [23]. The application of the selective CB1R agonist WIN55,212-2 (10 $\mu \mathrm{M})$ resulted in a long-lasting synaptic depression in both SAL and LPS rats. LTD amplitudes reached $44 \pm 6 \%(n=7)$ and $40 \pm 8 \%(n=5)$ in SAL and LPS rats, respectively. These magnitudes of LTD level were not significantly different from each other. 


\section{Discussion}

We find here that DHPG-induces an enduring potentiation of the excitatory synaptic transmission in the CA1 area of the hippocampus of rats challenged in utero with LPS. In fact, this form of plasticity, which could be named 'mGlu-LTP', recapitulates the features of the synaptic plasticity induced electrically with paired-pulse low frequency stimuli (so called 'ppulse-LFS-LTP') in these animals [7]. Indeed, we observe that mGlu1/5 activation triggers LTP instead of LTD in LPS rats. This mGlu-LTP occurs independently of NMDA receptor activation, since it is not affected by AP5 application. In addition, similar to ppulse-LFS-LTP, it also requires mGlu1 and mGlu5 activation. Therefore, there is a clear dysfunction of the pathways activated by mGlu1/5 in LPS animals as shown by their direct activation by a selective agonist. Nevertheless, there is one noticeable difference in their timing of appearance between mGlu-LTP and the ppulse-LFS-LTP obtained by afferent stimulation: mGlu-LTP in LPS animals lasts over 25 day-old of age while ppulse-LTP was generally extinguished after this age [7]. This suggests that mGlu1/5 dysfunction is enduring but other mechanisms should take place with development to limit mGlu-LTP as revealed by the loss of ppulse-LTP induced by electrical stimulation after 25 day-old of age.

There are many molecular mechanisms which could account for the disruption of mGlu-LTD in LPS animals. Our data agree with reduction in GABA-mediated inhibitory transmission and/or in NMDA receptor expression. Firstly, GABA accumulation via GAT-1 blockade with tiagabine inhibits DHPGinduced fEPSP potentiation in LPS rats. This indicates that mGlu-LTP could be partially attributed to a reduced inhibitory transmission, which leads to uncontrolled excitation. We have reported that electrically-induced LTD could be rescued in LPS animals by tiagabine [8]. Secondly, the reduction in NMDA receptors at synaptic sites could also be involved in this switch of plasticity. Indeed, blocking NMDA receptors results in the inhibition of mGlu-LTD in SAL animals, while mGlu-LTP is unaffected. Therefore, the presence of NMDA receptors could limit mGlu1/5 receptor activity, as shown previously by interaction studies between NMDA and mGlu5 receptors [24]. The presence of NMDA and mGlu5 receptors at synapses is regulated by intracellular scaffold proteins including Shank and Homer. Moreover, mutations in Shank genes have been associated with forms of autism [25-26]. Therefore, decreased expression of Shank could also account for the impairment of synaptic plasticity after prenatal stress. Alternatively, disruption of mGlu-LTD could also account for decreased functional interaction with cannabinoid CB1 receptors. Indeed, mGlu5 and CB1R agonists seem to activate common intracellular pathways leading to LTD in the CA1 area of the hippocampus [23]. In our hands, CB1R-mediated LTD appears to be rather unaffected by prenatal exposure to LPS. This suggests that this prenatal stress leads to some rather specific alterations of the mGlu1/5 receptors-associated pathways.

The functional relevance of this switch in synaptic plasticity in LPS animals, i.e. from LTD to LTP, obtained both electrically [7] or through the direct activation of mGlu1/5 remains to be elucidated at the behavioral level. In this line, mGlu1/5 activation is known to contribute to neurophysiological adaptations occurring during several forms of learning. For instance, mGlu5 activation contributes to the LTD evidenced in the hippocampus during spatial object recognition [27]. Therefore, such a switch in plasticity could be deleterious for correct learning acquisition. In support of this hypothesis, we have reported that spatial learning in the Morris' water-maze was greatly impaired in male rats subjected to such prenatal immune stress [5]. 
The mGlu-LTD appears to be dysregulated in a wide array of animal models recapitulating mental retardation and autism [17] and drug addiction [12]. It thus provides a robust parameter to probe synaptic deficits. According to the model considered, this form of LTD can be either enhanced or inhibited. Interestingly molecules modulating mGlu5, especially positive allosteric modulators, are exhibiting beneficial effects in alleviating the symptoms observed in different models of psychosis as those obtained by NMDA receptor blockade with MK-801 [28] or by Shank-3 genetic deletion [29]. Therefore, the direct modulation of mGlu1/5 receptors is becoming a promising route in the prospect of curing neurodevelopmental diseases. In addition, the dysfunction of mGlu1/5 receptors could also be attributed to some defects in receptor desensitizing mechanisms involving the GRK/Arrestin pathway. In this line, it has recently been shown that neuroinflammation induced by LPS exposure could sensitize mGlu receptor-associated responses through the downregulation of GRK2 protein [30]. Thus the dysfunction of $\mathrm{mGlu1/5}$ receptors that we observe here after prenatal stress could be due not only to alterations in receptor activation but also to modified mechanisms of receptor trafficking regulation in neurons. 


\section{References}

1-Atladóttir HO, Thorsen P, Østergaard L, Schendel DE, Lemcke S, Abdallah M, Parner ET (2010) Maternal infection requiring hospitalization during pregnancy and autism spectrum disorders. J Autism Dev Disord 40:1423-1430

2-Brown AS, Derkits EJ (2010) Prenatal infection and schizophrenia: a review of epidemiologic and translational studies. Am J Psychiatry 167:261-80

3- Hagberg H, Gressens P, Mallard C (2012) Inflammation during fetal and neonatal life: implications for neurologic and neuropsychiatric disease in children and adults. Ann Neurol 71:444-457

4-Boksa P (2010) Effects of prenatal infection on brain development and behavior: a review of findings from animal models. Brain Behav Immun 24:881-897

5-Lanté F, Meunier J, Guiramand J, Maurice T, Cavalier M, de Jesus Ferreira MC, Aimar R, Cohen-Solal C, Vignes M, Barbanel G (2007) Neurodevelopmental damage after prenatal infection: role of oxidative stress in the fetal brain Free Radic Biol Med 42:1231-1245

6-Lanté F, Meunier J, Guiramand J, De Jesus Ferreira MC, Cambonie G, Aimar R, Cohen-Solal C, Maurice T, Vignes M, Barbanel G (2008) Late N-acetylcysteine treatment prevents the deficits induced in the offspring of dams exposed to an immune stress during gestation. Hippocampus 18:602-609

7-Escobar M, Crouzin N, Cavalier M, Quentin J, Roussel J, Lanté F, Batista-Novais AR, Cohen-Solal C, De Jesus Ferreira MC, Guiramand J, Barbanel G, Vignes M (2011) Early, time-dependent disturbances of hippocampal synaptic transmission and plasticity after in utero immune challenge. Biol Psychiatry 70:992-999

8-Rideau Batista Novais A, Crouzin N, Cavalier M, Boubal M, Guiramand J, Cohen-Solal C, de Jesus Ferreira MC, Cambonie G, Vignes M, Barbanel G (2014) Tiagabine improves hippocampal long-term depression in rat pups subjected to prenatal inflammation. PLoS One Sep 3;9(9):e106302. doi: 10.1371/journal.pone.0106302

9-Volianskis A, France G, Jensen MS, Bortolotto ZA, Jane DE, Collingridge GL (2015) Long-term potentiation and the role of N-methyl-D-aspartate receptors. Brain Res 1621:5-16

10-Huber KM, Kayser MS, Bear MF (2000) Role for rapid dendritic protein synthesis in hippocampal mGluR-dependent long-term depression. Science 288:1254-1257

11-Fitzjohn SM, Kingston AE, Lodge D, Collingridge GL (1999) DHPG-induced LTD in area CA1 of juvenile rat hippocampus; characterisation and sensitivity to novel mGlu receptor antagonists. Neuropharmacology 38:1577-1583 
12-Lüscher C, Huber KM (2010) Group 1 mGluR-dependent synaptic long-term depression: mechanisms and implications for circuitry and disease. Neuron 65:445-459

13-Collingridge GL, Peineau S, Howland JG, Wang YT (2010) Long-term depression in the CNS. Nat Rev Neurosci 11:459-473

14-Bear MF, Huber KM, Warren ST (2004) The mGluR theory of fragile X mental retardation. Trends Neurosci 27:370-377

15-Knackstedt LA, Trantham-Davidson HL, Schwendt M (2014) The role of ventral and dorsal striatum mGluR5 in relapse to cocaine-seeking and extinction learning. Addict Biol 19:87-101

16-Hoffmann HM, Crouzin N, Moreno E, Raivio N, Fuentes S, McCormick PJ, Ortiz J, Vignes M (2016) Long-lasting impairment of mGluR5-activated intracellular pathways in the striatum after withdrawal of cocaine self-administration. Int J Neuropsychopharmacol doi: 10.1093/ijnp/pyw086. [Epub ahead of print]

17-D'Antoni S, Spatuzza M, Bonaccorso CM, Musumeci SA, Ciranna L, Nicoletti F, Huber KM, Catania MV (2014) Dysregulation of group-I metabotropic glutamate (mGlu) receptor mediated signalling in disorders associated with Intellectual Disability and Autism. Neurosci Biobehav Rev 46:228-241

18-Heuschkel MO, Fejtl M, Raggenbass M, Bertrand D, Renaud P (2002) A three-dimensional multielectrode array for multi-site stimulation and recording in acute brain slices. J Neurosci Methods 114:135-148

19- Lanté F, de Jésus Ferreira MC, Guiramand J, Récasens M, Vignes M (2006) Low-frequency stimulation induces a new form of LTP, metabotropic glutamate (mGlu5) receptor- and PKAdependent, in the CA1 area of the rat hippocampus. Hippocampus 16:345-360

20-Kopanitsa MV1, Afinowi NO, Grant SG (2006) Recording long-term potentiation of synaptic transmission by three-dimensional multi-electrode arrays. BMC Neurosci 7:61

21 Kingston AE, O'Neill MJ, Bond A, Bruno V, Battaglia G, Nicoletti F, Harris JR, Clark BP, Monn JA, Lodge D, Schoepp DD (1999) Neuroprotective actions of novel and potent ligands of group I and group II metabotropic glutamate receptors. Ann N Y Acad Sci 890:438-449

22-Gasparini F, Lingenhöhl K, Stoehr N, Flor PJ, Heinrich M, Vranesic I, Biollaz M, Allgeier $H$, Heckendorn R, Urwyler S, Varney MA, Johnson EC, Hess SD, Rao SP, Sacaan Al, Santori EM, Veliçelebi G, Kuhn R (1999) 2-Methyl-6-(phenylethynyl)-pyridine (MPEP), a potent, selective and systemically active mGlu5 receptor antagonist. Neuropharmacology 38:1493-1503

23 Izumi Y, Zorumski CF (2012) NMDA receptors, mGluR5, and endocannabinoids are involved in a cascade leading to hippocampal long-term depression. Neuropsychopharmacology 37:609-617

24-Perroy J, Raynaud F, Homburger V, Rousset MC, Telley L, Bockaert J, Fagni L (2008) Direct interaction enables cross-talk between ionotropic and group I metabotropic glutamate receptors. J Biol Chem 283:6799-6805 
25-Guilmatre A, Huguet G, Delorme R, Bourgeron T (2014) The emerging role of SHANK genes in neuropsychiatric disorders. Dev Neurobiol 74:113-122

26-lasevoli F, Tomasetti C, Buonaguro EF, de Bartolomeis A (2014) The glutamatergic aspects of schizophrenia molecular pathophysiology: role of the postsynaptic density, and implications for treatment. Curr Neuropharmacol 12:219-238

27-Goh JJ, Manahan-Vaughan D (2013) Endogenous hippocampal LTD that is enabled by spatial object recognition requires activation of NMDA receptors and the metabotropic glutamate receptor, mGlu5. Hippocampus 23:129-138

28-Rook JM, Xiang Z, Lv X, Ghoshal A, Dickerson JW, Bridges TM, Johnson KA, Foster DJ, Gregory KJ, Vinson PN, Thompson AD, Byun N, Collier RL, Bubser M, Nedelcovych MT, Gould RW, Stauffer SR, Daniels JS, Niswender CM, Lavreysen H, Mackie C, Conde-Ceide S, Alcazar J, Bartolomé-Nebreda JM, Macdonald GJ, Talpos JC, Steckler T, Jones CK, Lindsley CW, Conn PJ (2015) Biased mGlu5-Positive Allosteric Modulators Provide In Vivo Efficacy without Potentiating mGlu5 Modulation of NMDAR Currents. Neuron 86:1029-1040

29-Vicidomini C, Ponzoni L, Lim D, Schmeisser MJ, Reim D, Morello N, Orellana D, Tozzi A, Durante V, Scalmani P, Mantegazza M, Genazzani AA, Giustetto M, Sala M, Calabresi P, Boeckers TM, Sala C, Verpelli $C$ (2017) Pharmacological enhancement of mGlu5 receptors rescues behavioral deficits in SHANK3 knock-out mice. Mol Psychiatry 22:689-702

30-Degos V, Peineau S, Nijboer C, Kaindl AM, Sigaut S, Favrais G, Plaisant F, Teissier N, Gouadon E, Lombet A, Saliba E, Collingridge GL, Maze M, Nicoletti F, Heijnen C, Mantz J, Kavelaars A, Gressens P (2013) G protein-coupled receptor kinase 2 and group I metabotropic glutamate receptors mediate inflammation-induced sensitization to excitotoxic neurodegeneration. Ann Neurol. 73:667-678 
Figure 1: DHPG-evoked plasticity is altered in LPS-rats. DHPG $(100 \mu \mathrm{M})$ was applied for $10 \mathrm{~min}$ on hippocampal slices from either control (SAL) or LPS rats aged 16 day- to 6 month-old. fEPSP were recorded as described in the material and method section. A: While a significant long-term depression of fEPSP was observed in SAL rats ( $n=17)$, a significant LTP was induced in LPS rats $(n=19)$. Sample traces of fEPSP recorded either before (1 and 3) or 30min ( 2 and 4$)$ after the application of DHPG, in SAL (1 and 2) or LPS (3 and 4) rats, respectively are shown (top of the graph). ${ }^{*} \mathrm{p}<0.05$ versus basal fEPSP, using one way ANOVA for repeated measures followed by Holm-Sidak method for multiple comparisons; $\S p<0.05$ for comparison of LPS versus SAL, using two way ANOVA for repeated measures followed by Holm-Sidak method for multiple comparisons. B: Developmental profile (from 16 day old to 1 year old) of DHPG-induced plasticity in SAL or LPS rats. Amplitudes of fEPSP were determined either 30 or 35 min following DHPG application for SAL or LPS rats, respectively.

Figure 2: D-AP5 prevents the DHPG- induced LTD in SAL rats but not the DHPG-induced LTP in LPS rats. A: D-AP5 $(50 \mu \mathrm{M})$ was applied throughout fEPSP recording of hippocampal slices from either control (SAL) or LPS rats aged 11 day- to 3 month-old. Per se D-AP5 did not modify fEPSP amplitude. DHPG was applied for $10 \mathrm{~min}$. \# $p<0.05$ versus basal fEPSP, using one way ANOVA for repeated measures followed by Holm-Sidak method for multiple comparisons. N.S = non-significant. $\S p<0.05$ for comparison of LPS versus SAL, using two way ANOVA for repeated measures followed by HolmSidak method for multiple comparisons. B: Developmental profile of DHPG-induced plasticity in SAL or LPS rats in the presence of D-AP5. C: Summary histogram: Amplitudes of LTD or LTP were determined on a-15min plateau either 30 or 35 min following the DHPG stimulation for SAL or LPS rats, respectively. Values were compared to control fEPSP baseline using t-test: ${ }^{* *} p<0.01$; $* * * p<0.001$.

Figure 3: Similar DHPG-induced LTP is observed in LPS rats aged either under or over 25 day old. A: D-AP5 $(50 \mu \mathrm{M})$ was applied throughout fEPSP recording of LPS rat hippocampal slices and DHPG was applied for $10 \mathrm{~min}$. Data were separated in two groups according to the age of the animal, i.e. rats aged between 11 and 25 day old $(n=16)$, and rat aged over 25 day old $(n=13)$. B: Amplitudes of LTP were determined on a-15min plateau, $35 \mathrm{~min}$ following the DHPG stimulation. Values were compared to control baseline using t-test: ${ }^{*} p<0.05 ;{ }^{* *} p<0.01 ;{ }^{* * *} p<0.001$. Comparisons were also performed between the groups using ANOVA followed by Fisher LSD method; any significant difference was observed.

Figure 4: MPEP and LY367385 inhibit the DHPG-induced LTD in SAL rats. A: Either MPEP $(10 \mu M)$ or LY367385 $(100 \mu \mathrm{M})$ was applied 10 min prior to DHPG which was added for a further 10min on SAL rat hippocampal slices. ${ }^{*} p<0.05$ versus basal fEPSP, using one way ANOVA for repeated measures followed by Holm-Sidak method for multiple comparisons; N.S = non-significant. $\S p<0.05$ for 
comparison of values obtained either in the absence or the presence of antagonist, using two way ANOVA for repeated measures followed by Holm-Sidak method for multiple comparisons. B: Mean amplitudes of fEPSP were determined on a-15min plateau, $30 \mathrm{~min}$ following the DHPG stimulation. Values were compared to control baseline using t-test: ${ }^{*} p<0.05$. Comparison between values obtained either in the absence or the presence of the antagonist was performed using ANOVA followed by Fisher LSD method: \#p<0.05.

Figure 5: A: MPEP and LY367385 inhibit the DHPG-induced LTP in LPS rats in the presence of D-AP5. A: D-AP5 $(50 \mu \mathrm{M})$ was applied throughout fEPSP recording of hippocampal slices from LPS rats. MPEP $(10 \mu \mathrm{M})$ or LY367385 $(100 \mu \mathrm{M})$ was applied $10 \mathrm{~min}$ prior to DHPG which was added for a further 10min. B: Tiagabine inhibits the DHPG-induced LTP in LPS rats in the presence of D-AP5 or MK801. D-AP5 $(50 \mu \mathrm{M})$ or MK801 $(10 \mu \mathrm{M})$ was applied throughout fEPSP recording of hippocampal slices from LPS rats. Tiagabine $(20 \mu \mathrm{M})$ was applied 10 min prior to DHPG which was added for a further $10 \mathrm{~min} .{ }^{*}$ $p<0.05$ versus basal fEPSP, using one way ANOVA for repeated measures followed by Holm-Sidak method for multiple comparisons; NS = non-significant; $\S p<0.05$ for comparison of recording either in the absence or in the presence of drug, using two way ANOVA followed by Holm-Sidak method for multiple comparisons.

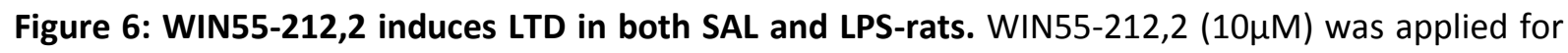
$10 \mathrm{~min}$ on hippocampal slices from either SAL $(n=7)$ or LPS $(n=5)$ rats. ${ }^{*} p<0.05$ versus basal fEPSP, using one way ANOVA followed by Holm-Sidak method for multiple comparisons. 

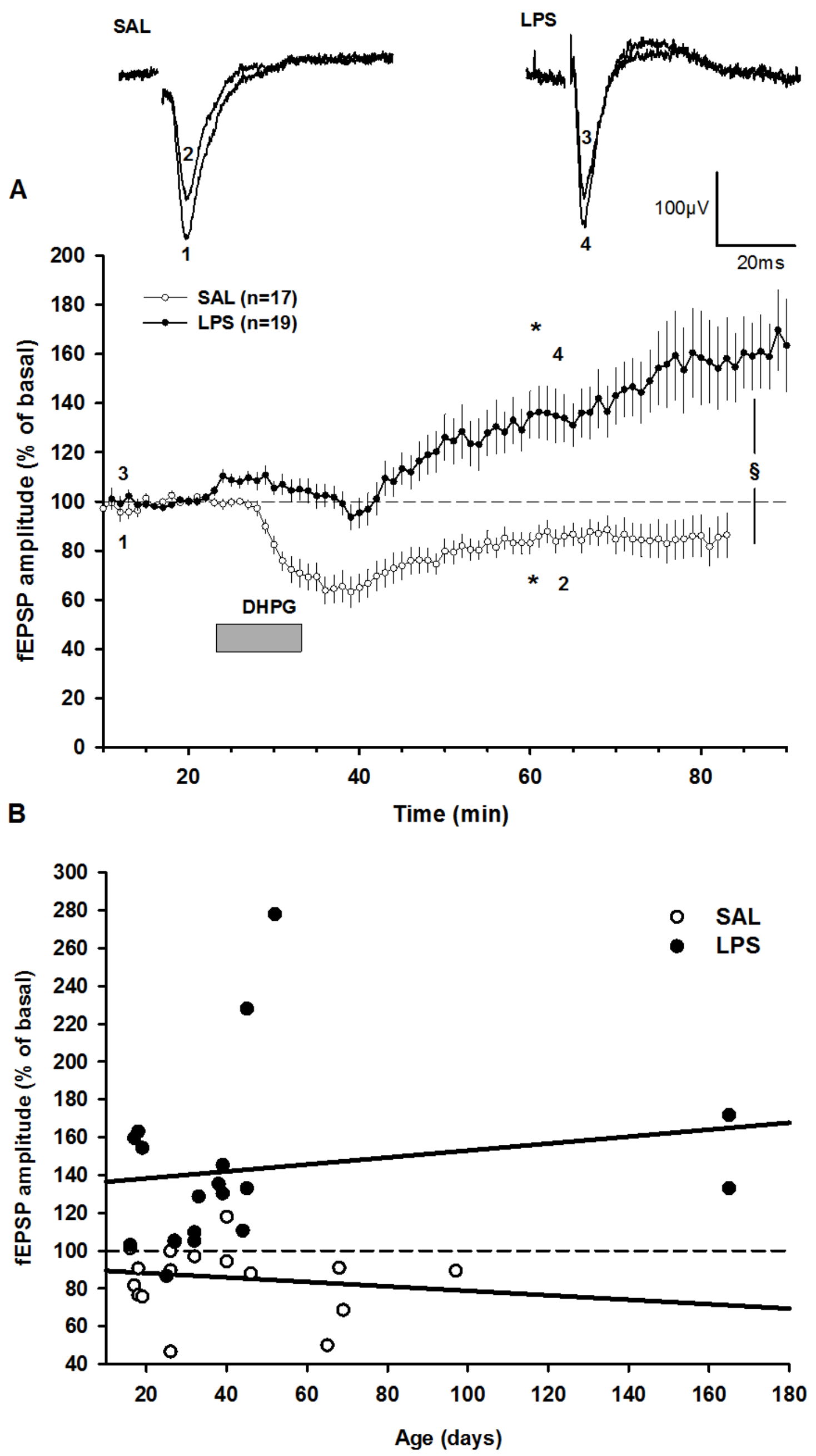
A

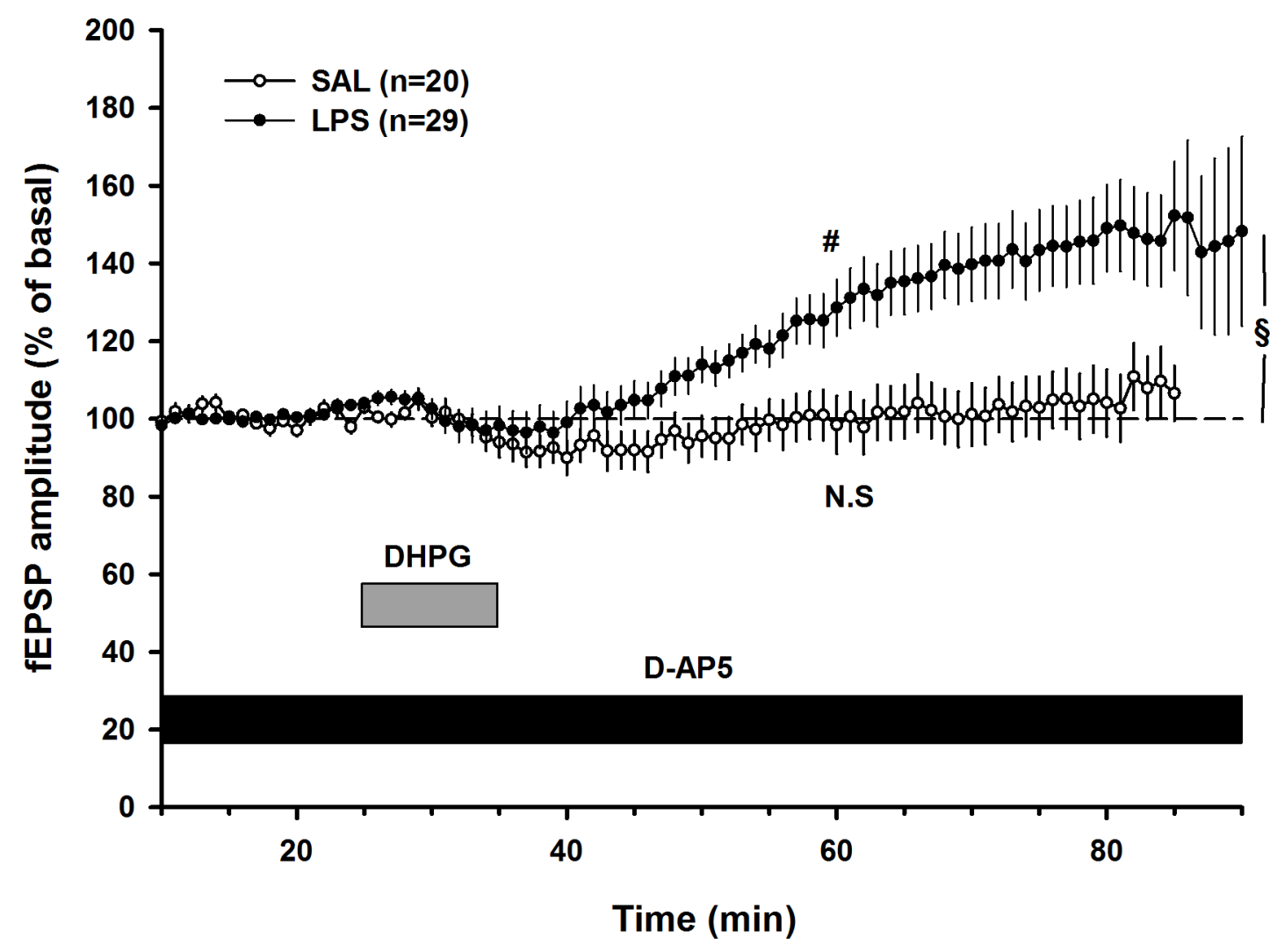

B

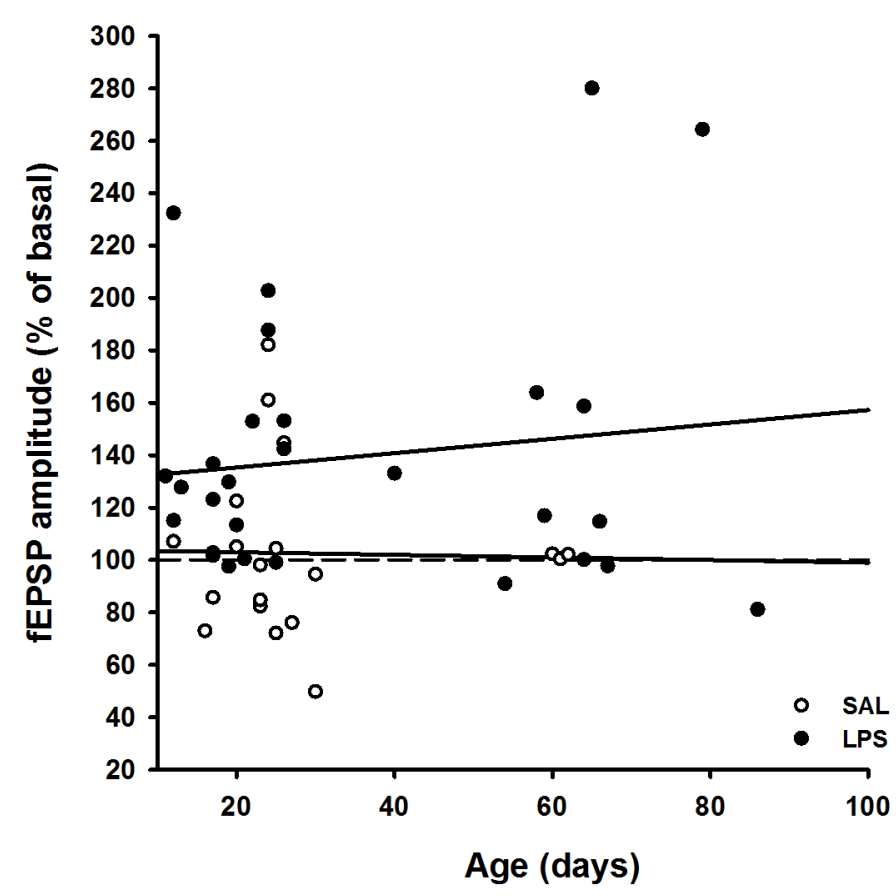

C

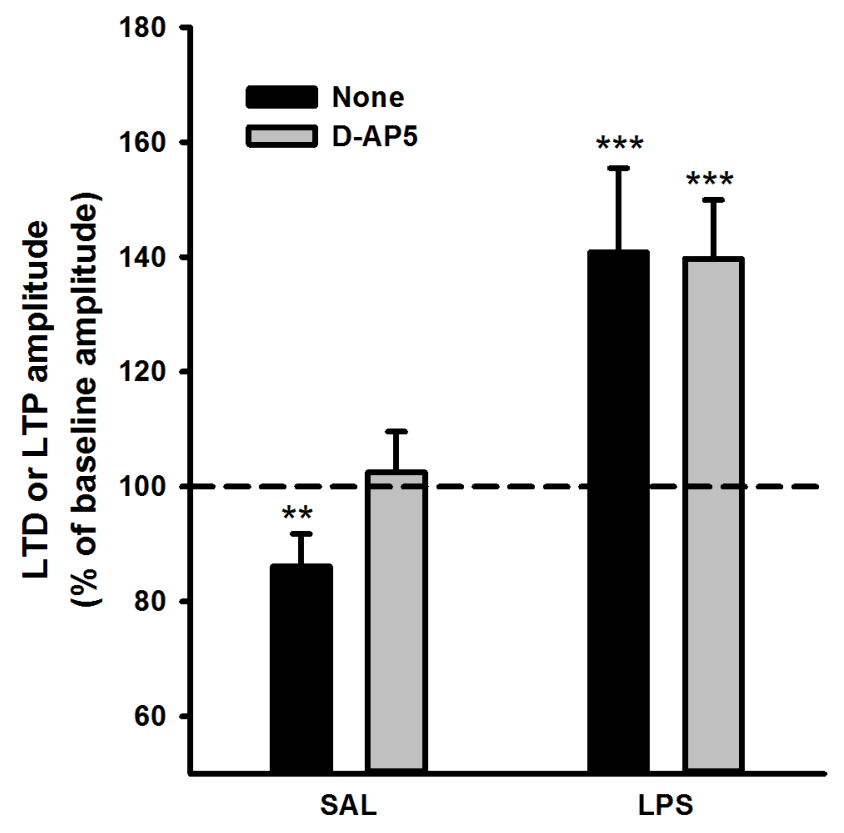




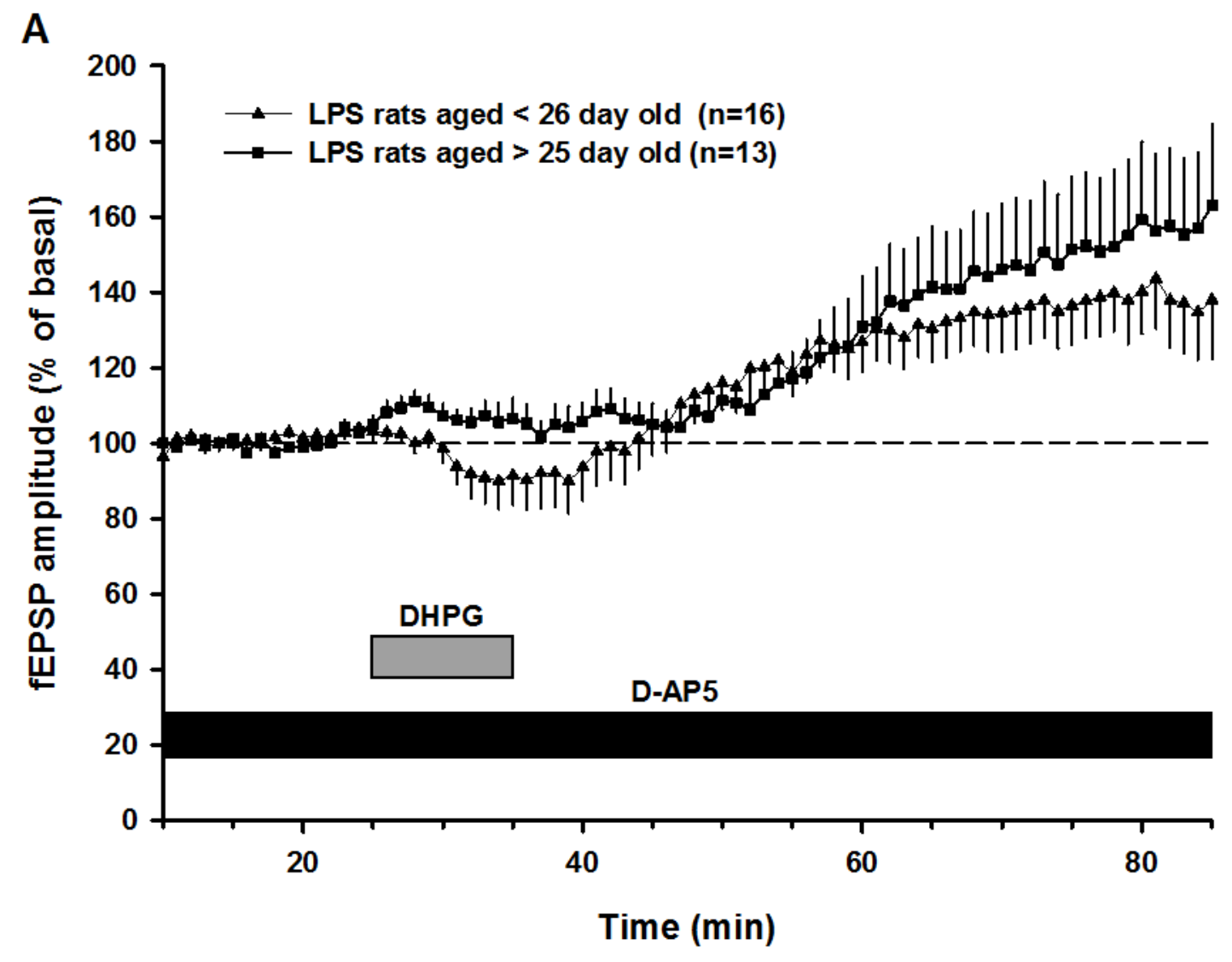

B

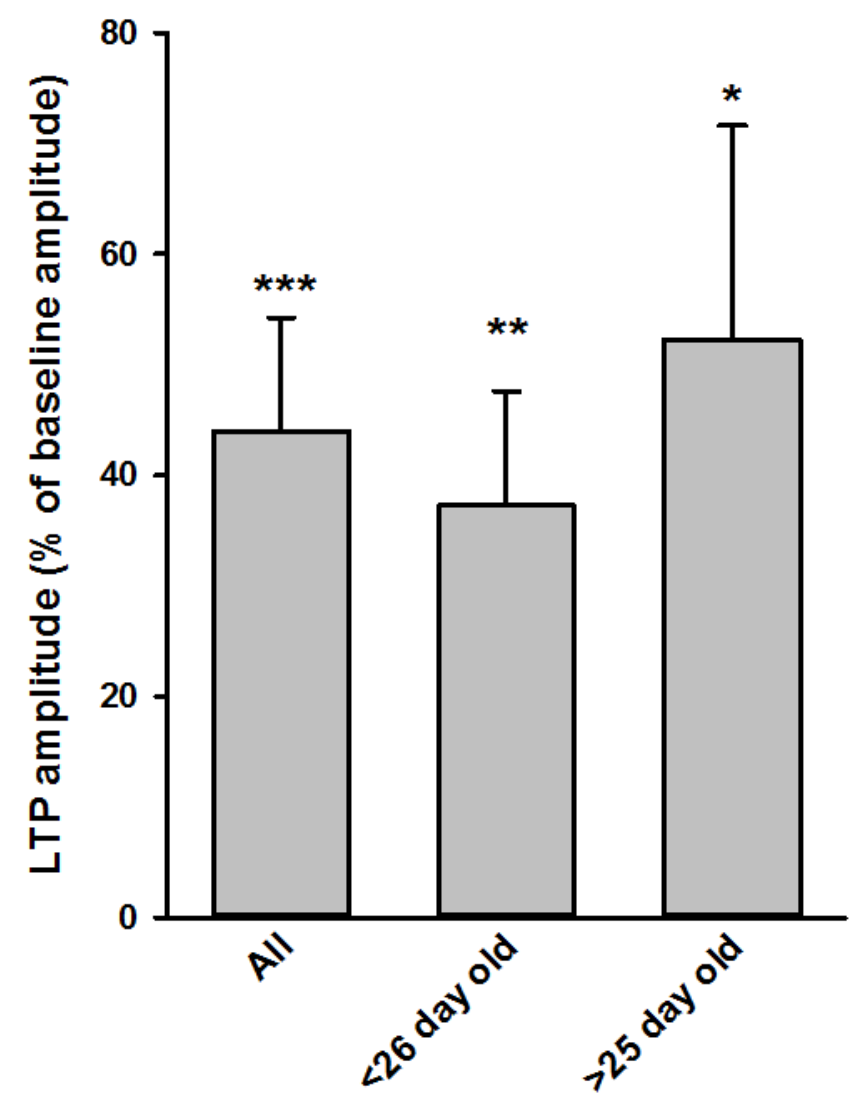



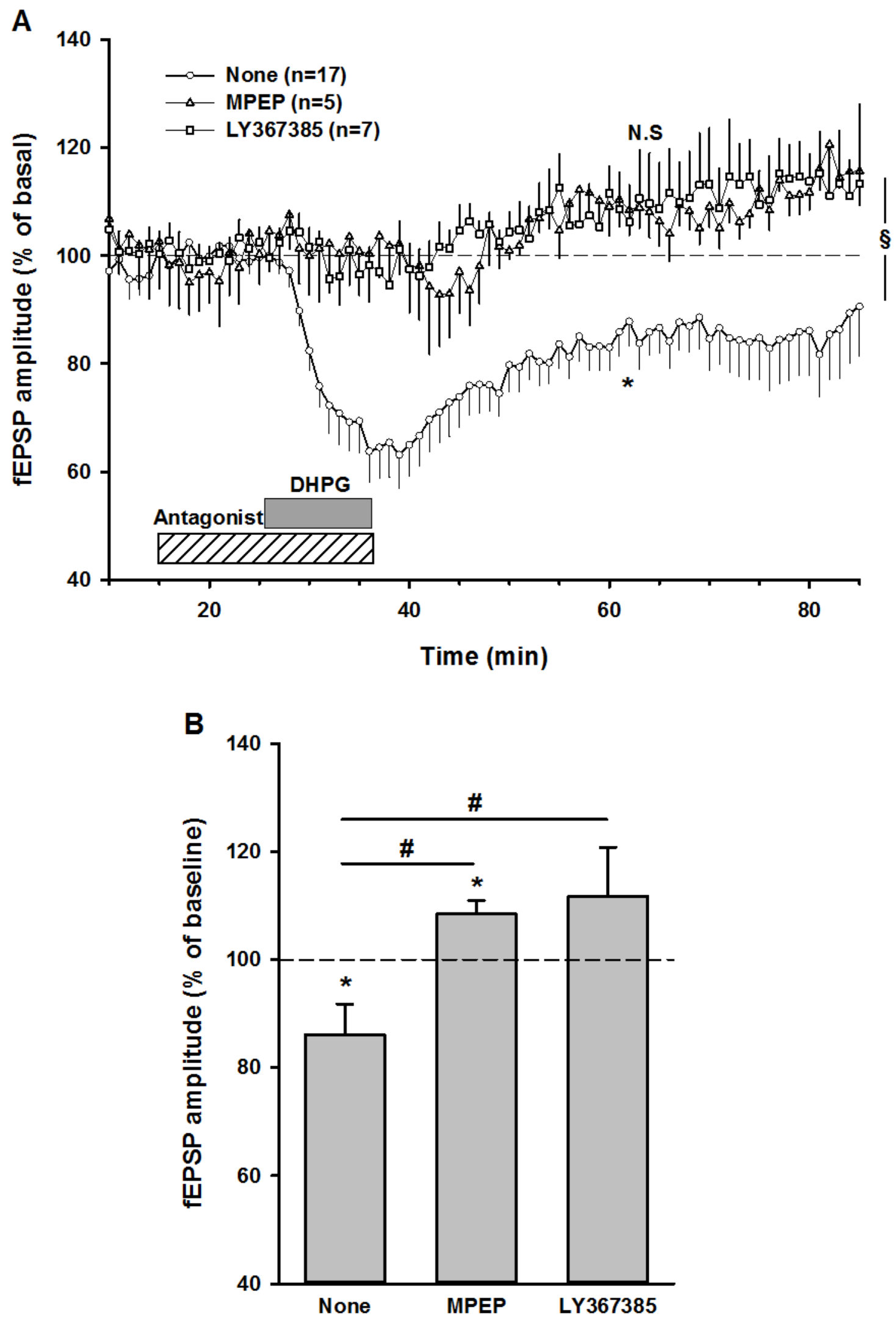


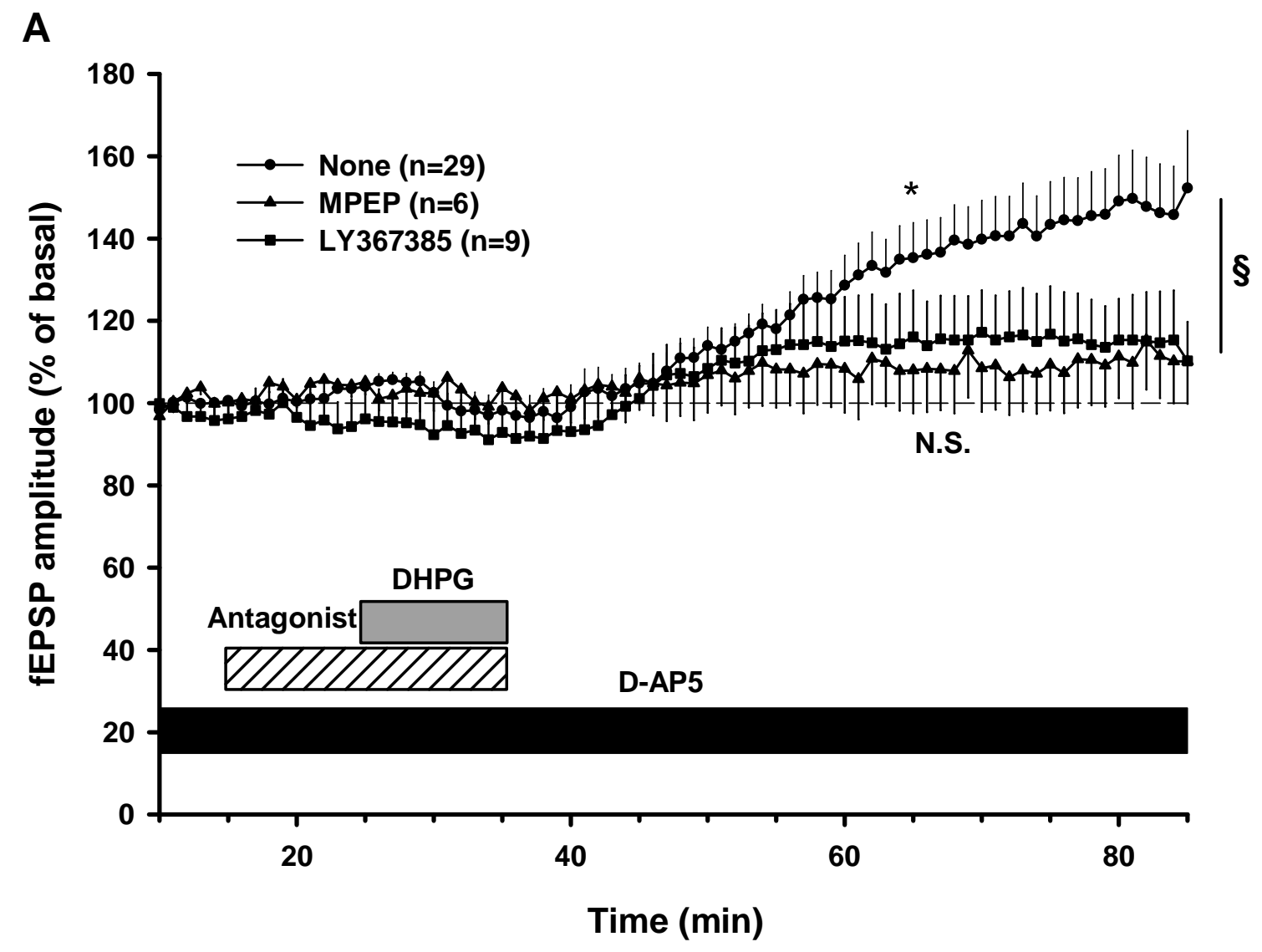

B

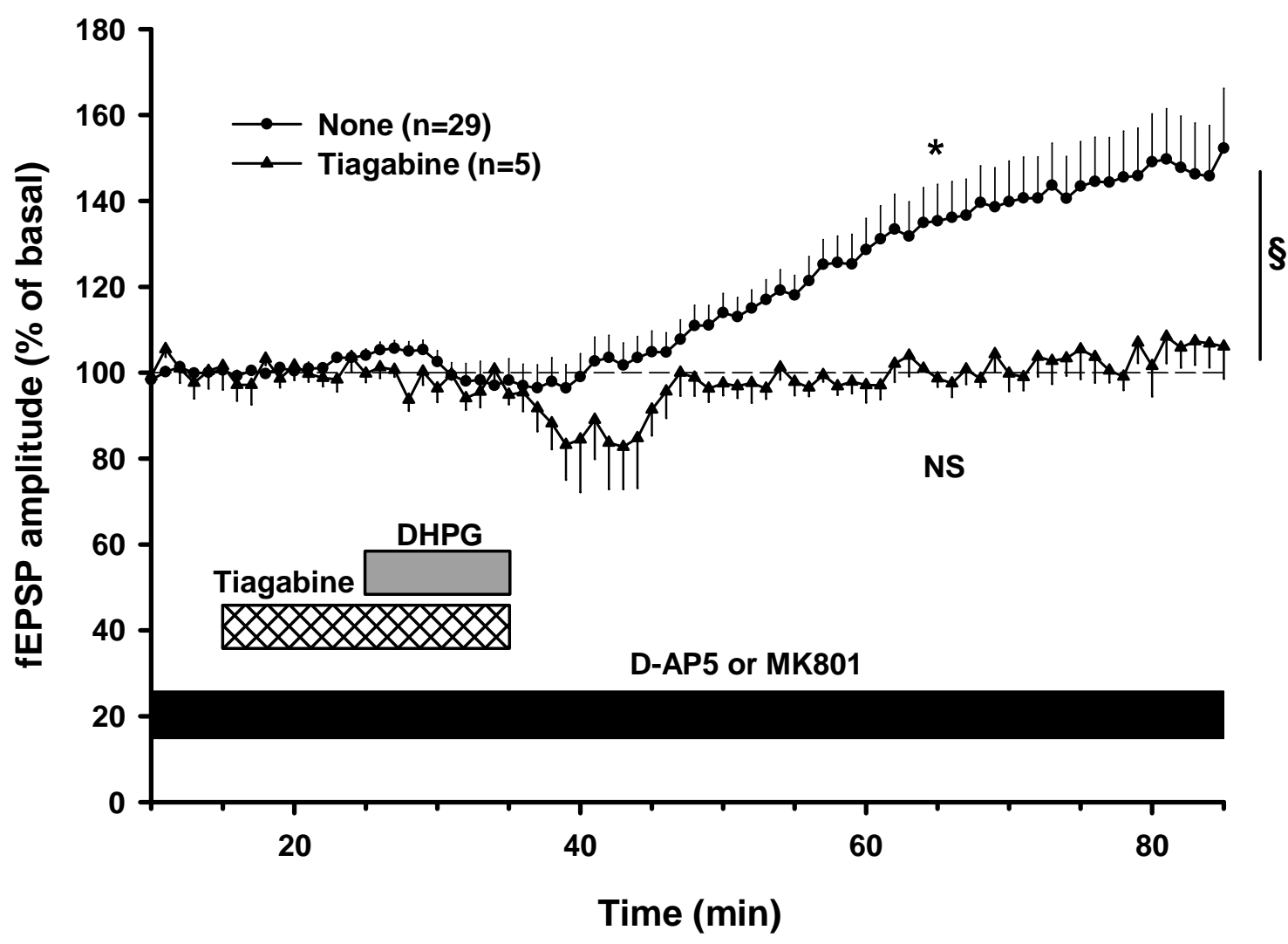




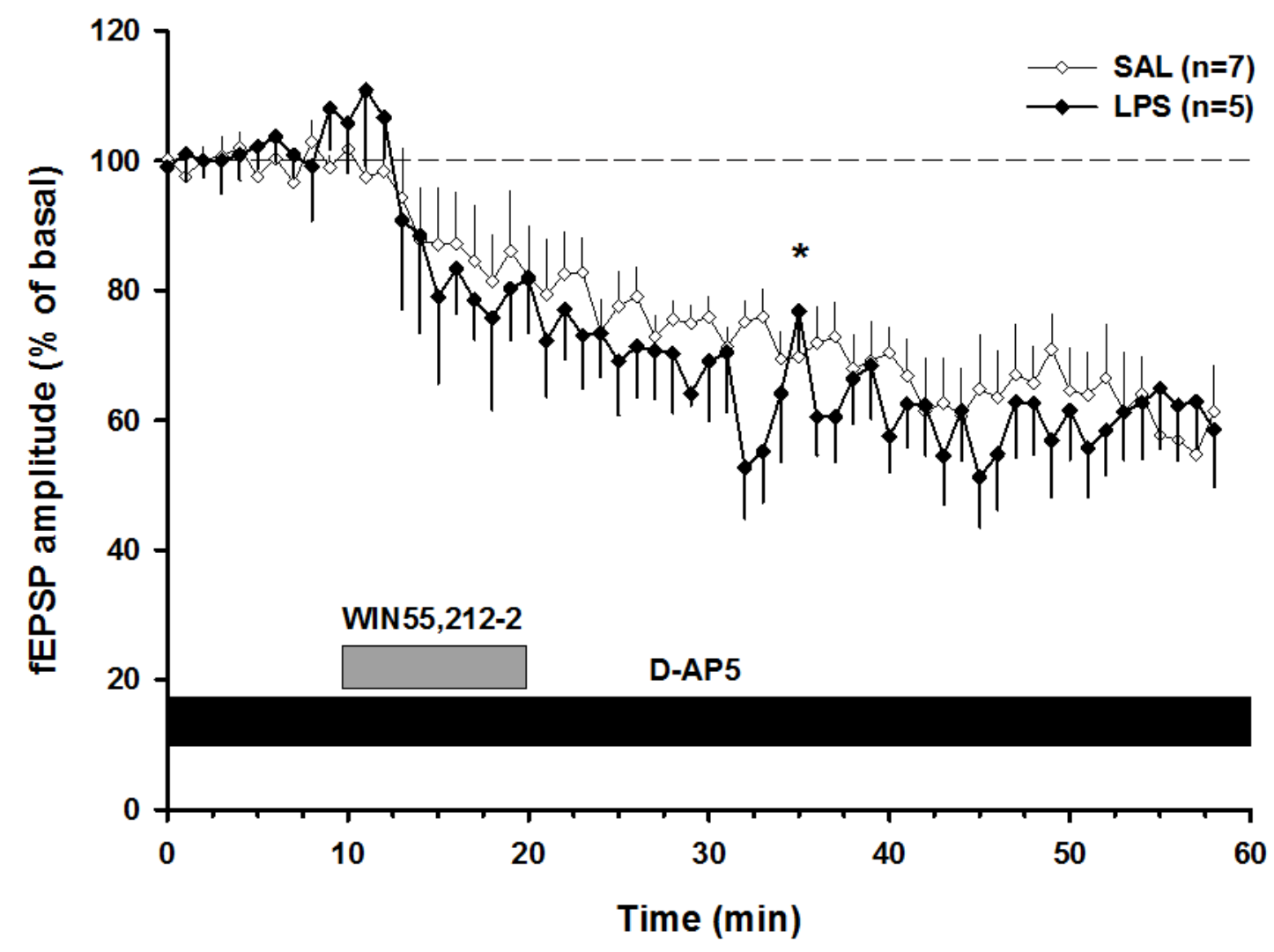

